\title{
Cutting to the Chase: Editing Jaws
}

\author{
Warren Buckland
}

In looking back over that final act of the movie, the seagoing sequence that took two and a half months to shoot and doubled the budget, [Spielberg] was right in recalling the pain, the frustration, the physical hardship, and the dogged weariness that went into making those last few reels. ${ }^{1}$

In the summer of 1975 Time magazine was not alone in praising Jaws for its "technically intricate and wonderfully crafted" filmmaking, achieved via "subtly correct camera placement and meticulous editing." ${ }^{2}$ Yet, the chaos and complexity of the shooting schedule, especially the final action sequence (chasing and killing the shark) is now legendary, with the non-functioning mechanical shark the main culprit. In her account of events, the film's editor Verna Fields also mentions the difficulties of filming on the open sea, which led to mix ups in scene numbers and continuity (particularly the number of barrels used to track the shark), and problems with matching the look of water, sky, and lighting conditions from one shot to the next, which were sometimes filmed months apart. ${ }^{3}$ The gulf between chaotic shooting schedule and the resulting "technically intricate and wonderfully crafted" film led to the suggestion that the film was 'saved' by Fields (the veteran editor who began her career in 1944 as assistant sound editor on Fritz Lang's Woman in the Window). Fields played down this suggestion, ${ }^{4}$ yet the studio backing the film, Universal, promoted her to an executive role, and she won an Oscar for her work on Jaws. 
Some directors leave editors little to do, for they plan their films down to the last shot or they do not shoot much coverage (shoot the same action from several different camera setups), while other directors shoot an enormous amount of coverage and leave the editor to choose the best angles (as well as the best takes). Film editor Ralph Rosenblum experienced both scenarios. He opens his memoir When the Shooting Stops ... The Cutting Begins with an account of how William Friedkin abandoned The Night They Raided Minsky's (1968) after seeing the first cut, leaving Rosenblum to sort through the forty hours of footage to rescue the film. ${ }^{5}$ Rosenblum also discusses the opposite situation, of having little footage to work with. Early in his career he edited the low budget gangster film Pretty Boy Floyd (Herbert J. Leder, 1960), which he says consisted mainly of scenes of two characters talking: "For each scene, I was

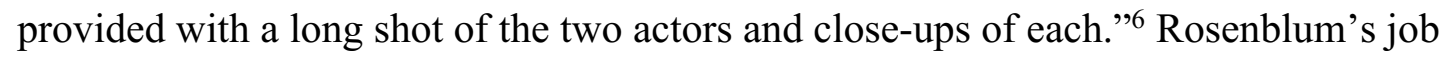
simply involved editing together the two close-ups and the establishing shot. There was very little creative leeway, resulting in a simple, mechanically edited film.

Verna Fields' experience was different. She preferred to work closely with directors, joining films at the production stage. ${ }^{7}$ Jaws was no exception: she was on location and assembled a rough cut of the first two acts of the film during production, and edited the final act (the chase sequence at sea) back in Hollywood. In an interview with Fields, Joseph McBride notes that "her editing as well as her advice in all areas of filmmaking were acknowledged as crucial to the success of such key 1970s films as Peter Bogdanovich's What's Up, Doc? [1972] and Paper Moon [1973], George Lucas's American Graffiti [1973], and Steven Spielberg's Jaws, for which she won an Academy Award." ${ }^{\prime}$ And screenwriter-actor Carl Gottlieb (who was also on location during the filming of Jaws) points out that "Steven enjoys close 
supervision of editing and is one of a breed of filmmakers who must see every edit, collaborate on every cut, and live with a picture from the initial planning through the final release print." ${ }^{, 9}$ Rather than try to single out the work of editor and director, I shall instead examine the editing in Jaws from technical and perceptual standpoints, in order to determine the significance of continuity editing in the final chase sequence.

\section{Method}

My method integrates into formal analysis the knowledge of film craft, or basic filmic techniques, embedded in part in filmmaking manuals. Karel Reisz and Gavin Millar's The Technique of Film Editing remains the seminal text for understanding the film editor's normative conventions and thinking processes. ${ }^{10}$ Drawing upon this technical knowledge creates an expanded mode of formal analysis, one based on a specialized understanding of how filmmakers think and work. This expanded type of criticism raises new issues to address when writing about films - issues practitioners face and solve on a day-to-day basis in making films.

The director, cinematographer, and editor work to create a seemingly effortless 'shot flow', whereby the final shots fit together in terms of continuity and physical changes. Roy Thompson identifies four types of continuity across cuts within a scene: continuity of content, of movement, of position, and sound. ${ }^{11}$ Physical changes across cuts include: symmetry, shot scale, camera angle, and movement (movement of actors within the shot and/or camera movement). In terms of cinematography, critics frequently discuss camera placement, but not always in terms significant to the director - its placement inside or outside the 'circle of action', or the decision-making process that leads to the judgement to switch from one to the other. 
In regards to technical editing knowledge, the ratio of camera setups to shots in a scene is significant in narrative cinema. Rarely is a setup used only once in a scene. More often, a setup is fragmented into several shots. How many setups does a director use in a scene, and how many shots does the editor create from those setups? Is the scene built upon discontinuity from shot to shot (cutaways, inserts) or is it based on the continuity of action from shot to shot? Does the editor allow dialogue to carry over a cut, or does he/she cut during a pause? What editing conventions does the editor rely on to create a sense of continuity (analytical cuts, directional continuity, eye-line matches, match on action cuts, shot/reverse shots, point of view editing)? Many of these editing conventions are planned before filming begins (they are everyday decisions made by directors and editors). However, when shooting a documentary or when filming on location, it is impossible to rigidly follow a storyboard due to unexpected factors. But Reisz observes that action sequences do at least offer the editor some leeway:

In assembling an action sequence the editor works with a much greater degree of freedom than in more static scenes where dialogue plays the predominant role. In a dialogue scene most of the visuals form an essential and unavoidable counterpart to the words and the editor is constantly tied down by the continuity of the words when cutting the picture. The visuals are anchored from the moment they are shot: the editor is merely able to choose between alternative shots and to time the cuts to the greatest dramatic effect. ${ }^{12}$ 
Action sequences are not usually hampered by synchronised dialogue, although the action sequence still needs to create a logical series of actions, achieved via a cumulative progression of a series of shots.

\section{Technical Innovations in Jaws}

Jaws displays a number of formal and technical innovations: (1) it effectively combines suspense, curiosity, and surprise; (2) it employs off-screen space for dramatic purposes; (3) it uses unattributed or delayed point of view (POV) shots from the shark's perspective; (4) it places the camera on the water's surface; (5) it has a memorable score; and (6) the editing of the final chase sequence exceeds the sum of its parts.

In this chapter I focus on the final innovation, but will give a brief overview of the others. The film's narrational strategies, especially the carefully planned shifts from restricted to omniscient narration, control the flow of story information to spectators, generating surprise, curiosity, and suspense. In restricted narration, important story information is withheld and is only revealed much later. If the spectator is not informed that crucial information was withheld, surprise is created when it is eventually revealed. But if the spectator is given hints and clues about the withheld information, curiosity is created. The spectator's restricted knowledge of story events is usually mirrored in a central character, such as a detective who, in attempting to piece together a crime, experiences curiosity and surprise when he or she uncovers the crucial information. In omniscient narration, by contrast, the spectator is conferred crucial story information, which is not initially conveyed to some or all of the characters. This results in a discrepancy of knowledge between character(s) and spectator, creating anticipation and suspense. ${ }^{13}$ 
Noël Burch defines the fundamental opposition in film space as that between on-screen and off-screen spaces. ${ }^{14}$ Onscreen space names the space inside the film frame, and off-screen space lies beyond the film frame, which is divided into six segments: the four spaces beyond each frame line, a fifth space (the space behind the camera), and a sixth space (the space hidden within the film frame). In Jaws, Spielberg uses off-screen space (especially the sixth space) proficiently to create surprise (when, for example, the shark suddenly emerges from the water, most famously when Brody is on the Orca boat throwing bait into the sea to attract the shark $\left.^{15}\right)$. In addition, Spielberg signals the off-screen presence of the shark via yellow barrels, which are attached to harpoons fired into the shark from a harpoon gun. The barrels act as an important on screen stand-in for the off-screen shark.

Spielberg also presents the opposite scenario: the film is punctuated by POV shots from the shark's perspective as it approaches unsuspecting victims (a moment of omniscient narration), although the shark's appearance is delayed, making the POV shot initially unattributed. What this means is that the origin of the glance (the shark) is not initially shown, but the glance itself is shown.

In regards to innovative cinematography and camera placement, neither the screenplay (by Peter Benchley and Carl Gottlieb) nor Tom Wright's storyboards conceived of filming parts of Jaws under water from the shark's perspective; nor did they conceive of filming at water level. The latter technique was made possible by cinematographer Bill Butler's invention of the water box. In response to a question about why he used the water box, he said:

The reason for using the water box is that you then have the ability to get the camera right at water level. You can literally let the water level rise up to the 
bottom of the lens without getting the camera wet. That's the only reason: just to keep the camera dry. It's nothing more than a square box; it looks like a fish tank. It has a solid bottom and the front is glass so that you can set a camera down in it. ${ }^{16}$

Butler's water box closely aligns spectators to the events in the water; it increases their psychological engagement with the film's events by placing them on the water's surface, inside the circle of action.

John Williams' score accompanies these innovative visual aspects of the film (precise camera placement and its movement through the water, representing the shark's POV). Giorgio Biancorosso argues that the accompaniment is literal: the first shark attack in the opening scene consists of several unattributed underwater POV shots accompanied by the 'Jaws theme', "an ostinato motive consisting of the alternation of two notes." ${ }^{\prime 17}$ Biancorosso goes on to argue that "it is only when we see the consequences of the upwardly moving shot, at the sound of the victim's screams, that the [musical] motive is wedded once and for all, if in retrospect, to [the shark]."18 The musical motive therefore comes to represent the shark's presence, filling in for the absence of the glance's origin in the unattributed POV shot.

\section{How to edit a chase scene}

Karel Reisz devotes Section 2 of The Technique of Film Editing to the practice of editing particular types of film sequences, beginning with the action sequence. He uses the chase at the end of Naked City (directed by Jules Dassin, edited by Paul Weatherwax, 1948) as an example. Reisz determines "how the editor has contrived [to create a] perfectly lucid continuity" 19 via the following techniques: 
- Crosscutting between pursued (the criminal Garza) and pursuer (the policeman Halloran)

- Cut away from pursuit to the police Chief (Muldoon)

- Variation in the rate of cutting to underline the changing tension in the action

- Repetition of camera set ups (pursued then pursuer traverse the same location filmed in the same manner; such repetition creates textual cohesion)

- Directional movement within the shot (characters run towards/away from camera; they run into or out of screen space)

- Each cut switches attention by showing a different location

Reisz argues that the key to a chase sequence is not rapid editing, as is commonly assumed, but the switch to a different location with each cut (a technique that incorporates the first two techniques, crosscutting and cutaways). Paul Weatherwax, the editor of Naked City, "has not cut the passage particularly fast, but has concentrated in switching the action around quickly among the three participants, in order to give the impression of the smoothly co-ordinated action of the two police contingents working together against the criminal." ${ }^{20}$ In the central part of the chase, "each cut takes us to another part of the action: there are no cuts which continue the action of the previous shot." ${ }^{21}$ This switching of attention (which is also a form of omniscient narration) creates the impression of fast action. There are in fact two pieces of action taking place: pursuer/pursued, plus Muldoon and his men. The chase sequence systematically cuts from the pursued to the pursuer, and then to Muldoon.

\section{Cuts in action}


The third act of Jaws comprises a chase sequence consisting of nine (loosely defined) scenes spread over 50 minutes (see Table 1). In this third act, the action is pared down to two possible outcomes: death of the shark/death of Quint, Hooper, and Brody. Negative tension is created by the severity of this future event. The second option seems more probable, which is gradually realized when the Orca begins to sink, Quint is killed, and Hooper disappears; but in the film's final state of affairs, the options are reversed, for Brody succeeds in killing the shark and Hooper reappears, dissipating the negative tension. ${ }^{22}$

\begin{tabular}{|l|l|}
\hline 1. & Out at sea. Early signs of tension between Quint, Hooper, and Brody. \\
\hline 2. & The shark is hooked on the fishing line but escapes. \\
\hline 3. & The shark surfaces and attacks the Orca. \\
\hline 4. & In the cabin, Quint, Hooper, and Brody drink and exchange stories. The shark attacks. \\
\hline 5. & $\begin{array}{l}\text { Quint and Hooper begin to repair the Orca, but the shark attacks again by dragging the } \\
\text { Orca and then chasing it; the Orca begins to sink. }\end{array}$ \\
\hline 6. & $\begin{array}{l}\text { Hooper goes into the water in a cage, but fails to kill the shark; instead, the shark almost } \\
\text { kills Hooper. }\end{array}$ \\
\hline 7. & $\begin{array}{l}\text { The shark kills Quint and almost kills Brody; but Brody manages to kill the shark by } \\
\text { shooting at the air tank in its mouth. }\end{array}$ \\
\hline 8. & Hooper resurfaces and swims back to shore with Brody. \\
\hline 9. & $\begin{array}{l}\text { Shot of the coastline with Brody and Hooper in the background reaching the shore. End } \\
\text { credits. }\end{array}$ \\
\hline
\end{tabular}

Table 1. Act Three of Jaws

Within scene 5 of the third act we can identify a conventionally edited chase (1.41:03 to 1.43 .47 on the DVD). This segment of film, comprising 31 shots and lasting 164 seconds, is united around a continuous piece of action, in which the shark chases the Orca. The segment begins with a shot of Quint starting up the engine and Hooper 
saying "He's chasing us. I don't believe it," and ends when the chase is over, with Brody and Hooper staring off screen at the shark (see Table 2).

\begin{tabular}{|c|c|}
\hline 1. Quint + Brody + Hooper & 17. Orca \\
\hline 2. Orca & 18. Barrels \\
\hline 3. Barrels & 19. Tachometer \\
\hline 4. Quint + Brody + Hooper & 20. Orca \\
\hline 5. Orca + barrels & 21. Hooper \\
\hline 6. Brody + Hooper & 22. Hooper \\
\hline 7. Quint + Brody + Hooper + barrels & 23. Engine cover (explosion) \\
\hline 8. Tachometer (RPM gauge) & 24. Brody \\
\hline 9. Hatch & 25. Quint \\
\hline 10. Orca & 26. Hooper \\
\hline 11. Quint + Brody + Hooper + barrels & 27. Engine cover \\
\hline 12. Barrels & 28. Quint and Hooper \\
\hline 13. Quint + Brody + Hooper + barrels & 29. Orca and barrels \\
\hline 14. Tachometer & 30. Barrels (+ Brody) \\
\hline 15. Hatch & 31. Brody and Hooper \\
\hline 16. Quint + Brody + Hooper + barrels & \\
\hline
\end{tabular}

Table 2 . The 31 shots of scene 5

These 31 shots can be grouped into seven types (defined in terms of content) (see Table 3):

a) Quint is in the foreground of this series of shots, with Hooper in the middle ground on the left, and Brody in the middle ground on the right. These six 
shots are evenly distributed throughout the first half of this segment. The camera position is the same - that is, the same camera setup is used and is divided into six shots, although the framing changes slightly, for the three barrels the shark is dragging along can be seen in the background of the final four shots $-7,11,13,16$ (see Figure 1).

b) The Orca is filmed either from the stern (shots 2, 5, 20, 29) or the bow (shots 10,17$)$, either with a still camera $(2,5,29)$, or a moving camera $(10,17$ and 20).

c) Similarly, the barrels are filmed from several angles: coming towards the camera $(3,12,29)$, moving away from the camera $(5,30)$, and filmed from the side (18). The segment as a whole therefore consists of repetition (the six shots of group [a]) and variation (different shots of the boat and barrels).

d) Brody and Hooper are filmed together on two occasions: in profile looking off screen left at the barrels (shot 6) and filmed facing the camera (looking off screen at the barrels) (shot 31). In this final shot they do not appear in the frame together, but successively, as the camera moves from Brody down to Hooper (Figures 2a and 2b). $<<$ insert Figures 1, 2a, and 2b here $>>$

e) Close ups of the tachometer (RPM gauge) are linked to Quint's awareness (he is aware of the tachometer directly in front of him, which he occasionally glances at). 
f) But shots of the hatch, where smoke begins to billow, do not represent any character's awareness; the three men on the boat do not see this event. Instead, these shots $(9,15)$ constitute omniscient narration and create suspense by giving the spectator more information than the characters, thereby setting up a hierarchy between the spectator and characters. (Quint can surmise that the engine is under pressure, but he can infer this from watching the tachometer, not from observing the hatch, which he cannot see from his position on the boat.)

g) Shot 23 continues to involve the camera. The engine explodes, and the cover moves rapidly towards the camera, almost hitting it. In fact, the engine explodes at the end of shot 22; the explosion in shot 23 is either a second explosion or, more likely, the same explosion filmed from a different angle and with a slight temporal overlap (less than half a second), which increases the explosion's effectiveness.

\begin{tabular}{|l|l|l|}
\hline a) & Quint + Brody + Hooper & 6 shots: $1,4,7,11,13,16$ \\
\hline b) & The Orca filmed from the water & 6 shots: $2,5,10,17,20,29$ \\
\hline c) & The three barrels & 4 shots: $3,12,18,30$ \\
\hline d) & Brody and Hooper & 2 shots: 6,31 \\
\hline e) & The gauge & 3 shots: $8,14,19$ \\
\hline f) & The hatch and engine cover & 4 shots: $9,15,23,27$ \\
\hline g) & Additional shots on the Orca & 6 shots: $21,22,24,25,26,28$ \\
\hline
\end{tabular}

Table 3. Seven types of shot in scene 5 
In shot 24 Brody is shown reacting to the explosion, but he does nothing. In shot 25

Quint grabs the fire extinguisher to put out the fire. He is filmed in close up and moves very close towards the camera. By the time the shot ends, he is exiting screen right, facing the camera just a few inches from it. In shot 26 Hooper gathers together his diving equipment, and in shot 27 Quint puts out the fire in the engine. Shots 21-27 switch the action around by cutting between the three men in their own spaces carrying out their own tasks, in contrast to the key establishing shot (a), repeated six times in the first half of the segment, which unites the three men and the shark in the same shot. The final shots mark the end of this segment, of the Orca stationary in the water and the shark swimming past, watched by Brody and Hooper.

As with the chase in Naked City, in Jaws moving towards/moving away from the camera is a significant structuring principle. In both films, the camera is not observing from a distance outside the circle of action, but is inside the circle of action. In shot 2, the Orca begins close to the camera but quickly moves away from it; in shot 3, the barrels move at great speed towards the camera, and the shot ends with the frame almost completely filled by the three barrels. These two shots therefore mark the beginning of the chase via the inversion of dynamic movement within the frame, divided by a 180 degree cut: the boat moves rapidly away from the camera / cut 180 degrees / the barrels move rapidly towards the camera.

This inverted dynamic movement, linked by a 180 degree cut, is mirrored in shots 21-22, of Hooper: in 21, he moves away from the camera and in shot 22 he moves towards the camera (where he jumps into some water in the boat's hull, splashing the camera, which is on the surface of the water in the water box). These two shots of Hooper are also linked via a 180 degree cut - but an inward cut, not outward. (In an inward 180 degree cut, the same subject is filmed, first from one side 
and then from the other side. In an outward 180 degree cut, the camera moves 180 degrees and points in the opposite direction, as is the case with shots 2-3.)

The first and last shots of this segment create textual cohesion by inverting one another. In shot 1 (Figure 1) Quint looks off screen towards the camera - to what Burch called the fifth space, the space behind the camera (in this instance, the boat's bow). The camera is still but the boat is moving. In shot 31 Brody and Hooper look off screen towards the camera - to the space behind the camera (in this instance, the boat's stern). The camera is moving but the boat is still (Figures $2 \mathrm{a}, 2 \mathrm{~b}$ ). This segment is punctuated by a specific event: Quint begins to steer the Orca to shore but burns out the engine, which explodes, incapacitating the boat and its crew. The segment is therefore divided into a 'before' and 'after': before the explosion, the space is united via the frame (the three men and the shark appear in the same shot) or via overlapping space and eye-line matches. After the explosion the space is fragmented, as each man occupies a separate space and the film cuts from one space to another space.

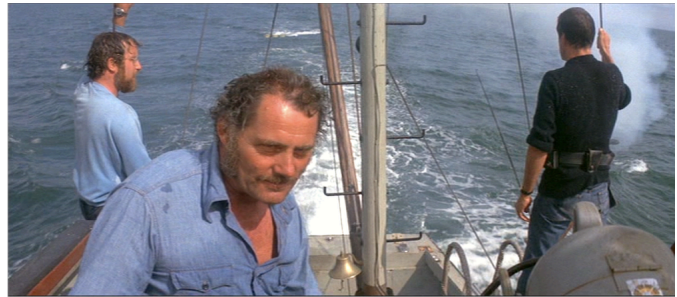

Figure 1

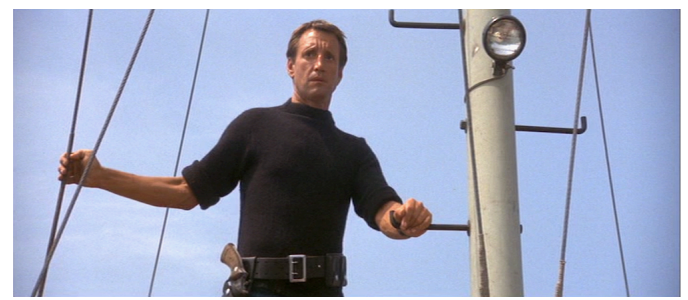

Figure 2a

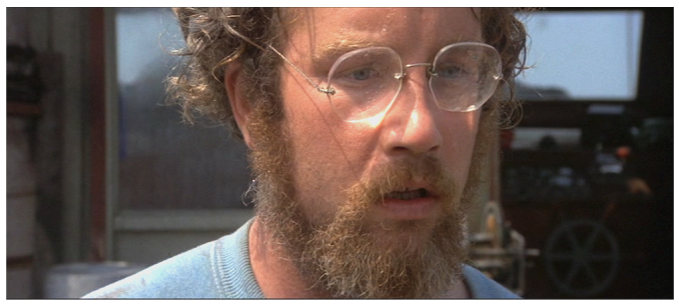

Figure 2b 


\section{Continuity}

Continuity of content, movement, position, and sound are maintained in this segment via several techniques. Firstly, there is the overlap of space between successive shots:

- 90 degree cuts (shots $5,6,7$ )

- Analytic cut (shots 12-13)

- 180 degree internal cut (shots 21-22: Hooper filmed from the back on the deck/Hopper filmed from the front inside the cabin)

- Spielberg maintains spatial unity of the pursuit by keeping pursuer-pursued in the same frame (in shots $5,7,11,13,16,29$, and 30 ).

In a 90 degree cut, parts of the same space appear on screen in successive shots, but are filmed from a different (90 degree) angle. It is the overlap of space and repetition of content from one shot to the next that helps to maintain continuity. In shot 5, Brody and Hooper appear in the background of a very long shot, staring out to sea towards the camera. In shot 6 , the camera moves 90 degrees to film Brody and Hooper in profile staring out to sea. In shot 7 the camera moves 90 degrees again, this time facing Quint steering the boat, with Brody and Hooper in the middle ground looking out to sea; they are now filmed from their back. In all three shots the action is continuous, but this action is filmed from successive 90 degree angles. The change from one shot to the next is not confusing, for the cuts maintain the physical geography of the space and the spectator's orientation in relation to that space.

In an analytic cut the camera points in the same direction, along the same axis; only the scale of the shot changes. Shot 12 shows the barrels from the perspective of 
the Orca's stern (but without showing the boat), and shot 13 shows the same action, but this time with the boat and crew in the foreground of the shot.

Secondly, a few of the shots are linked via an eye-line match: between shots 23 and 5-6 (Brody and Hooper / eye-line match / the barrels, on both occasions); and 13-14 (Quint / eye-line match / the tachometer). There is no overlap of space or action; instead, the successive shots are linked by the eye-line of an on screen character looking off screen, which motivates a cut to the off-screen object the character sees.

Thirdly, in terms of match on action cuts, Hooper's movement is matched over the cuts between shots 21-22 and 28-29; the movement of the barrels continues over shots 29-30; in shot 6 Brody stands up and in shot 7 the movement is completed (although it is possible to argue that the movement was completed just before the cut). The match on action draws attention away from the cut by maintaining the continuity of the action across the cut.

And fourthly, in regards to sound, music, and dialogue, orchestral music accompanies shots 1 to 6 ; the 'Jaws theme' is prominent when the barrels appear in shot 3 , linking the barrels to the shark. Diegetic sound dominates from shots 7 to $24-$ the sound of the boat's engine is continuous across the cuts, up to the moment the engine explodes. Shots 7 to 24 also contain fragments of synchronized dialogue and of Quint singing. When Quint grabs the fire extinguisher (shot 25), the orchestral music again takes over. There is no dialogue editing in this segment - that is, no dialogue cutting points, no speaking across cuts; instead, the dialogue is contained within the shots where it is spoken, with the exception of Quint's singing, which covers shots 16-20: 16) Quint on screen, 17) long shot of the Orca, 18) the barrels, 19) close up of the tachometer, and 20) long shot of the Orca. The singing is constant, 
steady, and continuous, even though the camera's distance from Quint varies significantly from shot to shot. Only in shot 16 is there direct synchronization of Quint's lips and the song. In this instance, the Jaws action segment under analysis confirms Reisz's observation that "in assembling an action sequence the editor works with a much greater degree of freedom than in more static scenes where dialogue plays the predominant role."

The continuity techniques identified in this segment of 31 shots from Jaws are deployed throughout the entire third act. In addition, shot/reverse shot is used in scene 4 (Quint, Hooper, and Brody drink and exchange stories), with Quint and Hooper initially in the main shots and Brody in the reverse shots, until Brody joins Quint and Hooper just before the shark attacks. Shot/reverse shot is also used extensively in scene 6 (Hooper goes into the water in a cage, although there is no dialogue editing, only Hooper speaking while is he on screen) and scene 7 (confrontation between Quint/the shark, and then Brody/the shark).

Continuity of content, movement, position, and sound, created via a cumulative progression of carefully edited shots, is key to the success of the film's third act - 'carefully edited' in terms of continuity techniques, but also in regards to the type of shots used, where they are placed, and how many times they appear. In other words, the success of the film's chase sequence is dependent on how the shots fit together to create shot flow.

\section{Conclusions}

In the classical Hollywood film Naked City, the editor's primary goal was to create and maintain continuity in order to convey the physical details of the scene (to maintain geographical location, consistent character movement and direction, plus the 
spectator's orientation in relation to the location and the characters). But in his analysis of the film's final chase sequence, Reisz points out that the continuity is not exact, because the pursuer-pursued appear to be very close to one another, running past the same spot in quick succession (the background is very similar). This is in fact more pronounced than Reisz states, for the pursuer-pursued run past the exact same spot more than once. Yet, this is not noticeable on first viewing, for spectators simply follow the action.

Shot 30 of the Jaws segment analysed in this chapter can be cited as an exception to the segment's reliance on continuity editing, for the shark is seen moving in the opposite direction in relation to the Orca. Of course, it could have turned around while the action focused on Quint, Hooper and Brody on the boat, but no image shows the shark changing direction. Nonetheless, the sudden change in direction is not jarring, for the shark had time to change direction (the change in direction is not instantaneous, which would have been jarring).

The third act of Jaws is plagued by another continuity issue: number of harpoons + barrels fired into the shark. The Orca has five barrels displayed prominently on the bow. In scene 3 of act 3, Quint fires one harpoon + barrel into the shark. In scene 5, he fires a second harpoon + barrel into the shark, and then the Orca chases the shark. However, only one barrel is visible in the water. Moments later, Quint fires a third harpoon + barrel, but only two are visible in the water, while three of the five barrels are visible on the boat. The shark then begins to drag the Orca along, and Quint's response is to fire another harpoon, this time while standing at the boat's stern (the other times he was standing on the bow). Quint's position creates a dramatic shot, for the barrel attached to the harpoon smashes through the window of the cabin, hits Brody in the face (knocking off his glasses) before it lands in the water. 
But we only see three barrels in the water, and two on deck, even though Quint has fired four harpoons + barrels at the shark. In scene 8 Brody and Hooper use the two remaining barrels (although there should only be one left) as flotation aids as they swim to shore.

This reveals what more than one professional editor has claimed - that continuity is not the only concern when joining shots together and choosing the cutting point. Cutting should primarily enhance the drama of the story, while technical accuracy is secondary. For example, Richard Pepperman argues that editors should cut "for value and impact - not matches." ${ }^{23}$ Editing needs to serve and enhance the dramatic situation of each scene, rather than mechanically follow rules of continuity. This principle as been taken to the extreme in what Steven Shaviro calls “post-continuity” cinema (Michael Bay, Tony Scott), in which "a preoccupation with immediate effects trumps any concern for broader continuity - whether on the immediate shot-by-shot level, or on that of the overall narrative." ${ }^{24}$ Spatial geography and continuity are relegated while delivering a series of shocks to spectators is privileged.

Joseph P. Magliano and Jeffrey M. Zacks identified three degrees of continuity in editing:

edits that are continuous in space, time, and action; edits that are discontinuous in space or time but continuous in action; and edits that are discontinuous in action as well as space or time. ${ }^{25}$

Edits following the conventions of continuity editing do not hinder the perception of actions and events, while discontinuities in space and/or time have minor effects (the 
changes in space and time become noticeable but do not disrupt the comprehension of actions and events). After all, each cut by its very nature creates an instantaneous displacement in space (and sometimes in time), which is only partly disguised by the techniques of continuity editing - directional continuity, match on action, eye-line match, sound bridge, etc. (Here I disagree with Magliano and Zacks, for no cut is continuous in space.) But discontinuity of action suggests an event boundary - the end of one event and the beginning of another. If the same action is presented in a discontinuous manner, it can lead to confusion. Magliano and Zacks conclude that the primary aim of continuity editing is therefore to maintain the continuity of action and events within scenes, with the continuity of space and time in themselves of secondary importance, a conclusion reached by other cognitive psychologists. ${ }^{26}$ The coherence of the text is therefore less important than the coherence of the represented actions and events. Post-continuity can thereby be defined in terms of what Magliano and Zacks call "edits that are discontinuous in action as well as space or time." The inconsistency of harpoons + barrels in Jaws is a borderline case: on the one hand it signifies an inconsistency in the action, while on the other hand it remains secondary to the stark narrative conflict between the shark/the three men on the boat. Spectators attending to the film's narrative events are engaged with this conflict, not with idly counting barrels, especially in a medium where perception is temporally constrained (the next shot usually arrives within a matter of seconds). In addition, one study of eye tracking in narrative film (replicated in other studies) concluded that the spectator's region of interest (the part of the screen they focus on) is on average around $12 \%$ of the entire screen, usually the centre. ${ }^{27}$ What this means is that, when viewing a film in real time, spectators tend to focus on the $10-12 \%$ of the screen where the main action is unfolding. We can transpose this observation from spectacle 
to narrative, which similarly creates a narrow zone of interest that focuses attention on key actions and events rather than all actions and events taking place on screen. In Jaws, the number of barrels (although not the barrels themselves) would tend to fall outside this narrow zone of narrative interest.

Nonetheless, there are notable differences between scenes that employ techniques of continuity editing and those that violate these techniques. Magliano and Zacks suggest that scenes violating the conventions of continuity editing are not remembered as well as scenes that follow the conventions (for it is more difficult to construct a mental representation of the actions and events), and that discontinuous scenes lead to an increase in eye movement. ${ }^{28}$ Of course, each cut necessarily creates discontinuity and heightens the spectator's visual attention, as he or she searches for the main point of interest after the cut, but the techniques of continuity editing disguise the cut, and thereby minimise discontinuity and eye movement.

From the short analysis carried out in this chapter, and from the experiments carried out by cognitive psychologists, we can conclude that shot flow and strict adherence to the conventions of continuity editing are not necessary for the basic comprehension of actions and events in a narrative film, but that they nonetheless constitute 'added value' that can be appreciated by filmmakers and cinéphiles - such as the Time reviewer who found Jaws to be a "wonderfully crafted" film due to the way it exploited basic filmic techniques such as camera placement and editing.

\section{Notes}

\footnotetext{
${ }^{1}$ Carl Gottlieb, The Jaws Log, expanded edition (New York: Newmarket Press, 2012), 143.

${ }^{2}$ Anon. "Summer of the Shark," Time, 105, no. 26 (23 June 1975). Academic Search

Complete, EBSCOhost (accessed July 25, 2018).
} 
${ }^{3}$ See Joseph McBride, "The Editor: Verna Fields," in Filmmakers on Filmmaking: The American Film Institute Seminars on Motion Pictures and Television, Volume 1, ed. Joseph McBride (Los Angeles: J.P. Tarchner, Inc., 1983), 144. For another informed eyewitness account of the film's final action sequence, see Gottlieb, The Jaws Log, especially 162-63.

${ }^{4}$ See McBride, "The Editor: Verna Fields," 144.

${ }^{5}$ Ralph Rosenblum, with Robert Karen, When the Shooting Stops ... the Cutting Begins: A Film Editor's Story, new edition (Cambridge, MA: Da Capo Press, 1986), 11-30.

${ }^{6}$ Rosenblum, When the Shooting Stops, 135.

${ }^{7}$ See McBride "The Editor: Verna Fields," 141-42; and Gottlieb, The Jaws Log, 103-4.

${ }^{8}$ McBride "The Editor: Verna Fields," 139.

${ }^{9}$ Gottlieb, The Jaws Log, 104.

${ }^{10}$ Karel Reisz and Gavin Millar, The Technique of Film Editing, second edition (London: Focal Press 1968). Reisz wrote the first part of this book (13-272) and Gavin Millar wrote the second part (279-387). In this chapter I will only be quoting from Reisz's section.

${ }^{11}$ Roy Thompson, Grammar of the Edit (Oxford: Focal Press, 1993), 48-49.

${ }^{12}$ Reisz, The Technique of Film Editing, 84.

${ }^{13}$ For a detailed analysis of the concepts of 'surprise', 'curiosity', and 'suspense', see William Brewer, "The Nature of Narrative Suspense and the Problem of Rereading," in Suspense: Conceptualizations, Theoretical Analyses, and Empirical Explorations, ed. Peter Vorderer, Hans J. Wulff, and Mike Friedrichsen (Mahwah, N.J.: L. Erlbaum Associates, 1996), 107-27. ${ }^{14}$ Noël Burch, Theory of Film Practice, translated by Helen R. Lane (Princeton: Princeton University Press, 1981), 17-31.

${ }^{15}$ This moment in the film in fact creates a combination of surprise (the spectator and Brody were unaware of the shark's presence just below the surface of the water) and a few seconds of suspense (for the spectator briefly sees the shark before Brody sees it, for he is facing away from the water). 
${ }^{16}$ Bill Butler, in Dennis Schaefer and Larry Salvato, Masters of Light: Conversations with Contemporary Cinematographers (Berkeley: University of California Press), 91.

${ }^{17}$ Giorgio Biancorosso, "The Shark in the Music," Music Analysis, 29, no. 1/3 (2010): 306.

${ }^{18}$ Ibid., 309.

${ }^{19}$ Reisz, The Technique of Film Editing, 74.

${ }^{20}$ Ibid., 76.

${ }^{21}$ Ibid.

${ }^{22}$ As with all narratives, there cannot be a sense of satisfaction and relief if the negative tension does not exist. See Dolf Zillmann, "The Psychology of Suspense in Dramatic Exposition," in Suspense: Conceptualizations, Theoretical Analyses, and Empirical Explorations, ed. Peter Vorderer, Hans J. Wulff, and Mike Friedrichsen (Mahwah, N.J.: L. Erlbaum Associates, 1996), 199-231 (especially 220-27).

${ }^{23}$ Richard Pepperman, The Eye is Quicker. Film Editing: Making a Good Film Better (Studio City, CA: Wiese), 27.

${ }^{24}$ Steven Shaviro, Post-Cinematic Affect (Winchester: Zero Books, 2010), 123. See also Steven Shaviro, "Post-Continuity: An Introduction," in Post-Cinema: Theorizing 21stCentury Film, ed. Shane Denson and Julia Leyda (Falmer: REFRAME Books, 2016), 51-64. ${ }^{25}$ Joseph P. Magliano and Jeffrey M. Zacks, “The Impact of Continuity Editing in Narrative Film on Event Segmentation," Cognitive Science 35 (2011): 1489.

${ }^{26}$ In their experimental study of eye movements following cuts, Filip Germeys and Géry d'Ydewalle conclude that: important changes in the visual scene, due to the changed camera position, do not really disturb the viewer. The experiment provides evidence against the hypothesis that violating editing rules causes large degrees of confusion or ruins the representation of a scene. In terms of visual perception, the Formal Editing Principle (Hollywood editing rules), which emphasizes smooth transitions between shots, does not need to be followed strictly; the findings are thus more in agreement with the 
modern viewpoint which states that perceptual inconsistencies between shots are easily overcome by the narrative structure of the movie. (Filip Germeys and Géry d'Ydewalle, “The Psychology of Film: Perceiving Beyond the Cut," Psychological Research 71 [2007]: 465)

${ }^{27}$ Robert B. Goldstein, Russell L. Woods, and Eli Peli, "Where People Look When Watching Movies: Do All Viewers Look at the Same Place?” Computers in Biology and Medicine 37 (2007): 957-64.

${ }^{28}$ Magliano and Zacks, "The Impact of Continuity Editing," 1511, and references in Ed Tan, "Film-Induced Affect as a Witness Emotion," Poetics 23 (1994): 28, note 19.

Published in:

The Jaws book: New perspectives on the classic summer blockbuster [ISBN: 9781501347528] / edited by I.Q. Hunter and Matthew Melia (Bloomsbury, 2020). 